\title{
Genotypic and environmental variation in specific leaf area in a widespread Alpine plant after transplantation to different altitudes
}

\author{
J. F. Scheepens $\cdot$ Eva S. Frei $\cdot$ Jürg Stöcklin
}

Received: 27 April 2009 / Accepted: 20 April 2010 / Published online: 12 May 2010

(C) Springer-Verlag 2010

\begin{abstract}
Specific leaf area (SLA) is an important plant functional trait as it is an indicator of ecophysiological characteristics like relative growth rate, stress tolerance and leaf longevity. Substantial intraspecific variation in SLA is common and usually correlates with environmental conditions. For instance, SLA decreases with increasing altitude, which is understood as adjustment to temperature. It is generally assumed that intraspecific variation is mostly the result of environmentally induced phenotypic plasticity, but genetic effects may also be present, due to local adaptation or genetic drift. In this study, genotypic and environmental effects on SLA were experimentally separated for the widespread Alpine bell flower Campanula thyrsoides by transplanting plants to three common gardens at contrasting altitudes $(600,1,235$ and $1,850 \mathrm{~m}$ a.s.l.). Seeds were sampled from 18 populations in four phylogeographic regions within the European Alps. A strong plastic response was observed: SLA decreased with increasing altitude of the common gardens $(22.0 \%$ of variation). The phylogeographic regions were differentiated in SLA in the common gardens (10.1\% of variation), indicating that SLA is at least partly genetically determined. Plants from the six easternmost populations experienced a submediterranean climate and showed decreased SLA values in the three common gardens compared to populations to the west, which may be explained as adaptation to drought. Within these submediterranean populations, SLA decreased with altitude of
\end{abstract}

Communicated by Meelis Partel.

J. F. Scheepens $(\square) \cdot$ E. S. Frei · J. Stöcklin

Section of Plant Ecology, Institute of Botany,

University of Basel, Schönbeinstrasse 6,

4056 Basel, Switzerland

e-mail: jf.scheepens@unibas.ch origin in two out of three common gardens. Concluding, SLA shows strong phenotypic plasticity as well as substantial genetic effects, the latter probably being the result of adaptation to local conditions rather than genetic drift.

Keywords Altitude of origin - Campanula thyrsoides . Genetic effect - Local adaptation · Phenotypic plasticity

\section{Introduction}

The study of functional plant traits is a useful approach when searching for answers to a broad range of research questions. At the interspecific level, functional traits can be used to explain community composition and structure (Weiher and Keddy 1999; Lavorel and Garnier 2002; Díaz et al. 2004). Functional traits can also be used to classify plant species according to strategies sensu Grime (1977) or to explain the occurrence and distribution of species (Díaz et al. 1998). At the intraspecific level, functional traits often show considerable variability that is usually assumed to be of adaptive significance.

One of the most informative functional traits is specific leaf area (SLA) (Lavorel and Garnier 2002; Wright et al. 2004; Westoby and Wright 2006; Poorter et al. 2009) as it is an indicator of ecophysiological characteristics such as relative growth rate, stress tolerance and leaf longevity (Weiher et al. 1999; Wright and Westoby 2002). It is calculated as one-sided leaf surface area per unit dry weight. A higher SLA indicates decreased leaf thickness, decreased leaf density, or a combination of both. Poorter et al. (2009) report SLA to range interspecifically from 5 to $>3,333 \mathrm{~cm}^{2} \mathrm{~g}^{-1}$, but within-species variation can be large as well. For example, Cordell et al. (1998) report SLA for the Hawaiian endemic Metrosideros polymorpha to range 
from 24.6 to $93.5 \mathrm{~cm}^{2} \mathrm{~g}^{-1}$ across an altitudinal gradientan almost fourfold difference. SLA correlates strongly with temperature, irradiance and water availability (Poorter et al. 2009). Among as well as within species, SLA generally decreases with increasing altitude (Morecroft and Woodward 1996; Körner 2003, p 212; Milla et al. 2009), which is most likely a response to decreasing temperature rather than increasing radiation (Körner 2003) or to changes in water availability (Poorter et al. 2009).

It is generally assumed that functional traits are highly plastic. However, whether and, if so, to what extent intraspecific variation in functional traits is due to strict genetic control, environmentally induced phenotypic plasticity or a combination of both remain open questions. Although there have been reports of genetic effects on SLA (e.g. Morecroft and Woodward 1996), most studies focus on phenotypic plasticity alone (Poorter et al. 2009). Phenotypic plasticity allows a genotype to adjust its trait values to a range of environmental conditions (Bradshaw 1965; Schlichting 1986; Sultan 2000). In the case of SLA, values may change as new leaves develop, thereby conferring continuous adaptation to the environment during plant growth (Sims and Pearcy 1992). In contrast, any genetic effects influencing SLA may hamper such a rapid adjustment; in that case, changes in SLA come about by natural selection of those individuals possessing trait values that are well adapted to the current environment-a process taking place on a time scale of generations (Jump and Peñuelas 2005). Thus, phenotypic plasticity allows for a more rapid and flexible adjustment to environmental change than genetically fixed adaptations (Sultan 2000). It follows that the extent to which SLA is phenotypically plastic or genetically fixed has important implications for the survival probability of populations under changing environmental conditions.

By growing plants from different populations in a common environment, i.e. common garden experiments, researchers can determine genetic differentiation in traits among those populations (Turesson 1922; Clausen et al. 1940). When multiple common gardens situated in contrasting environments are used, phenotypic plasticity can be shown by means of different trait values among the gardens. However, common garden experiments do not suffice when local adaptation is the focus of the study; in such cases, reciprocal transplantation experiments are necessary (Kawecki and Ebert 2004). However, the case for local adaptation can be strengthened by other sources of evidence. For example, local adaptation is likely if a trait measured in a common garden correlates with an environmental variable at the locations of origin (Linhart and Grant 1996; Ennos 2001). In addition, the case for local adaptation is strengthened if drift can be excluded by showing the absence of isolation-by-distance and by demonstrating a significantly stronger or weaker quantitative differentiation in the studied traits compared to neutral molecular differentiation ( $Q_{\mathrm{ST}}$ vs. $F_{\mathrm{ST}}$ comparisons; Rogers 1986; Spitze 1993; McKay and Latta 2002).

In the study reported here, genotypic and environmental variation in SLA were experimentally separated for Campanula thyrsoides L. (Campanulaceae), a monocarpic species distributed widely across the European Alps. Seeds were collected from 18 populations from four major Alpine biogeographic regions and across a large altitudinal range, and derived plants were grown in three common gardens at contrasting altitudes. The biogeographic regions probably reflect Quaternary postglacial recolonization patterns (Merxmüller 1952, 1953, 1954; Ozenda 1988). Intraspecific differentiation of neutral genetic markers of several plant species has been shown to correlate with these four biogeographic regions (Schönswetter et al. 2005) and has likewise been described for $C$. thyrsoides (Kuss et al. unpublished). In our study, a response of SLA to the altitude treatment after 10 weeks of growth in the common garden experiment would indicate phenotypic plasticity, whereas differentiation among regions or populations would indicate genetic effects (Bradshaw 1965, 1984; Galen et al. 1991; Sultan 2000). Significant interactions between the altitude treatment and regions or populations would indicate genetic variation in phenotypic plasticity. In order to investigate whether any genetic effects were due to local adaptation or genetic drift (Linhart and Grant 1996), SLA was correlated with the altitude of population origin, while climatic differences between the Eastern Alps and the higher populations to the west were also taken into account. The altitude of origin functioned as a substitute for a score of environmental variables changing with altitude, most notably temperature (Monty and Mahy 2009). Additionally, isolation-by-distance in SLA was determined, and a $Q_{\mathrm{ST}}$ versus $F_{\mathrm{ST}}$ comparison was performed to check for past natural selection on this trait.

In summary, the aim of our study was to investigate the following three research questions: (1) does the functional trait of SLA show phenotypic plasticity in Campanula thyrsoides? Specifically, does SLA respond to transplantation to different altitudes? (2) Are there any genetic effects at the regional or population level? (3) Is there any evidence suggesting local adaptation of SLA?

\section{Methods}

Campanula thyrsoides L. is a monocarpic bell flower occurring in subalpine and alpine calcareous grasslands. Its main distribution is across the Jura and the European Alps. The altitudinal range is typically from 1,600 to $2,200 \mathrm{~m}$ a.s.l. (Kuss et al. 2007), although it can reach much higher altitudes (2,900 m a.s.l., Val Mora, Switzerland; Brunies 
1906 in Kuss et al. 2007) as well as much lower altitudes, especially in the Dinaric Alps, where the lowest population has been found at $217 \mathrm{~m}$ a.s.l. (Gracnica, Slovenia; J. Stöcklin, personal observation). The species occurs in isolated populations, yet can be locally abundant. Initiation of flowering is dependent on the rosette size, and flowering age ranges from 3 to 16 years, with an average of about 10 years (Kuss et al. 2007, 2008).

Campanula thyrsoides is taken as the model species in this study because it rapidly replaces its leaves after transplantation to different altitudes, which allows changes in SLA to be investigated within a short time frame. C. thyrsoides seeds were sampled from several mother plants from 18 populations over a broad altitudinal range (283-2,266 m a.s.1.) across four biogeographic regions spanning the Jura and the Alps (Ozenda 1988; Table 1). The biogeographic regions are denoted from west to east as Western Alps, Central Swiss Alps, Central Austrian Alps and Eastern Alps, respectively. Starting in September 2007, seeds were germinated on moist filter paper in petri dishes and kept under controlled light and moisture conditions in a greenhouse located in Basel, Switzerland (276 $\mathrm{m}$ a.s.1.). After germination, seedlings were planted into 4-cm diameter pots filled with low-nutrient soil (Anzuchterde; Ökohum, Herrenhof, Switzerland). After 10-18 weeks, the plants were repotted into $10 \times 10 \times 10$-cm pots containing potting soil (Topferde; Ökohum). The plants were sprayed several times with insecticide during growth to control Aphidoidea and Sciaridae outbreaks. Fertilizer was added once during growth in the greenhouse. In the spring, the plants were transferred to an outside garden to acclimatize before the final transplantation.

On 24 June 2008, the rosette diameter of each plant was measured to the nearest $0.5 \mathrm{~cm}$, and the plants were transplanted to common gardens in three fenced sites at different altitudes $(600,1,235$ and $1,850 \mathrm{~m}$ a.s.1.) on the southeastfacing slope of Mt. Calanda, near Chur, Switzerland. Plants were planted into the local soil which was topped with sterilized soil to limit weed germination. The distances between the three sites did not exceed 2,500 m based on the longitudinal and latitudinal positions. It should be noted that the plants were observed to replace their leaves immediately after transplantation. On 2 September 2008 (10 weeks after transplantation), the rosette diameter of

Table 1 Locations of sampled Campanula thyrsoides populations and the experimental sites (region, latitude, longitude, altitude, annual precipitation and yearly minimum, mean and maximum temperatures based on monthly averages; Hijmans et al. 2005)

\begin{tabular}{|c|c|c|c|c|c|c|c|c|c|}
\hline Locations of sites & Code & Region & Latitude & Longitude & $\begin{array}{l}\text { Altitude } \\
\text { (m a.s.1.) }\end{array}$ & $\begin{array}{l}\text { Precipitation } \\
(\mathrm{mm})\end{array}$ & $T_{\min }\left({ }^{\circ} \mathrm{C}\right)$ & $T_{\text {mean }}\left({ }^{\circ} \mathrm{C}\right)$ & $T_{\max }\left({ }^{\circ} \mathrm{C}\right)$ \\
\hline \multicolumn{10}{|l|}{ Sampling site } \\
\hline Les Amburnez & JUA & WA & $46^{\circ} 32^{\prime} 27.52^{\prime \prime} \mathrm{N}$ & $6^{\circ} 13^{\prime} 58.57^{\prime \prime} \mathrm{E}$ & 1,340 & 1,539 & -6.5 & 5.1 & 18.8 \\
\hline Col du Marchairuz & JUM & WA & $46^{\circ} 33^{\prime} 06.27^{\prime \prime} \mathrm{N}$ & $6^{\circ} 15^{\prime} 13.46^{\prime \prime} \mathrm{E}$ & 1,440 & 1,695 & -7.5 & 3.9 & 17.2 \\
\hline Trient, Les Tseppes & TRI & WA & $46^{\circ} 02^{\prime} 53.93^{\prime \prime} \mathrm{N}$ & $6^{\circ} 58^{\prime} 47.05^{\prime \prime} \mathrm{E}$ & 2,020 & 1,672 & -9.3 & 1.9 & 14.8 \\
\hline Lac du Fully & FUL & WA & $46^{\circ} 10^{\prime} 09.96^{\prime \prime} \mathrm{N}$ & $7^{\circ} 06^{\prime} 09.51^{\prime \prime} \mathrm{E}$ & 2,100 & 1,780 & -9.8 & 1.0 & 13.3 \\
\hline Lac du Moiry & MOI & WA & $46^{\circ} 08^{\prime} 12.78^{\prime \prime} \mathrm{N}$ & $7^{\circ} 34^{\prime} 02.87^{\prime \prime} \mathrm{E}$ & 2,266 & 1,827 & -10.3 & -0.1 & 11.6 \\
\hline Stockhorn & STO & CSA & $46^{\circ} 41^{\prime} 37.05^{\prime \prime} \mathrm{N}$ & $7^{\circ} 32^{\prime} 16.72^{\prime \prime} \mathrm{E}$ & 1,980 & 1,700 & -8.3 & 2.3 & 14.4 \\
\hline Schynige Platte, pop 4 & SP4 & CSA & $46^{\circ} 39^{\prime} 17.31^{\prime \prime} \mathrm{N}$ & $7^{\circ} 54^{\prime} 16.67^{\prime \prime} \mathrm{E}$ & 1,911 & 1,716 & -8.5 & 2.0 & 13.8 \\
\hline Schynige Platte, pop 18 & SP18 & CSA & $46^{\circ} 39^{\prime} 33.73^{\prime \prime} \mathrm{N}$ & $7^{\circ} 55^{\prime} 14.41^{\prime \prime} \mathrm{E}$ & 1,930 & 1,716 & -8.5 & 2.0 & 13.8 \\
\hline Churwalden, Joch & $\mathrm{CHJ}$ & CAA & $46^{\circ} 47^{\prime} 51.41^{\prime \prime} \mathrm{N}$ & $9^{\circ} 33^{\prime} 53.65^{\prime \prime} \mathrm{E}$ & 1,890 & 1,520 & -9.6 & 0.2 & 10.8 \\
\hline Langwies, Holzbüel & $\mathrm{LAH}$ & CAA & $46^{\circ} 49^{\prime} 41.97^{\prime \prime} \mathrm{N}$ & $9^{\circ} 44^{\prime} 00.53^{\prime \prime} \mathrm{E}$ & 1,700 & 1,095 & -7.7 & 3.6 & 16.1 \\
\hline Langwies, Listboden & LAL & CAA & $46^{\circ} 51^{\prime} 07.02^{\prime \prime} \mathrm{N}$ & $9^{\circ} 45^{\prime} 32.22^{\prime \prime} \mathrm{E}$ & 2,000 & 1,326 & -9.1 & 1.1 & 12.3 \\
\hline Ftan Prui & FTA & CAA & $46^{\circ} 48^{\prime} 32.68^{\prime \prime} \mathrm{N}$ & $10^{\circ} 13^{\prime} 20.37^{\prime \prime} \mathrm{E}$ & 2,101 & 1,383 & -10.6 & -1.1 & 9.3 \\
\hline Sella Nevea & SEL & EA & $46^{\circ} 23^{\prime} 35.00^{\prime \prime} \mathrm{N}$ & $13^{\circ} 27^{\prime} 46.00^{\prime \prime} \mathrm{E}$ & 932 & 1,253 & -8.7 & 4.0 & 18.1 \\
\hline Loibelpass & LOI & EA & $46^{\circ} 25^{\prime} 51.80^{\prime \prime} \mathrm{N}$ & $14^{\circ} 15^{\prime} 38.10^{\prime \prime} \mathrm{E}$ & 1,068 & 1,242 & -7.7 & 6.0 & 21.4 \\
\hline Sklendrovice & SKL & EA & $46^{\circ} 06^{\prime} 22.60^{\prime \prime} \mathrm{N}$ & $14^{\circ} 59^{\prime} 56.10^{\prime \prime} \mathrm{E}$ & 339 & 1,219 & -5.0 & 8.8 & 24.8 \\
\hline Nemski Rovt & NEM & EA & $46^{\circ} 16^{\prime} 23.50^{\prime \prime} \mathrm{N}$ & $15^{\circ} 00^{\prime} 53.85^{\prime \prime} \mathrm{E}$ & 663 & 1,180 & -6.6 & 7.3 & 23.1 \\
\hline Brodnice & $\mathrm{BRO}$ & EA & $46^{\circ} 06^{\prime} 24.30^{\prime \prime} \mathrm{N}$ & $15^{\circ} 16^{\prime} 53.10^{\prime \prime} \mathrm{E}$ & 283 & 1,132 & -4.6 & 9.5 & 25.6 \\
\hline Vitanje & VIT & EA & $46^{\circ} 22^{\prime} 27.80^{\prime \prime} \mathrm{N}$ & $15^{\circ} 17^{\prime} 16.90^{\prime \prime} \mathrm{E}$ & 422 & 1,086 & -5.6 & 8.9 & 25.0 \\
\hline \multicolumn{10}{|l|}{ Experimental sites } \\
\hline Lowest site & & & $46^{\circ} 52^{\prime} 18.34^{\prime \prime} \mathrm{N}$ & $9^{\circ} 31^{\prime} 05.45^{\prime \prime} \mathrm{E}$ & 600 & & & & \\
\hline Intermediate site & & & $46^{\circ} 53^{\prime} 11.29^{\prime \prime} \mathrm{N}$ & $9^{\circ} 29^{\prime} 42.76^{\prime \prime} \mathrm{E}$ & 1,235 & & & & \\
\hline Highest site & & & $46^{\circ} 52^{\prime} 48.69^{\prime \prime} \mathrm{N}$ & $9^{\circ} 30^{\prime} 36.10^{\prime \prime} \mathrm{E}$ & 1,850 & & & & \\
\hline
\end{tabular}

WA Western Alps, CSA Central Swiss Alps, CAA Central Austrian Alps, EA Eastern Alps 
each plant was measured again, and a total of 594 plants were sampled for SLA: 204 individuals at the lowest site $(600 \mathrm{~m}), 183$ at the intermediate site $(1,235 \mathrm{~m})$ and 207 at the highest site $(1,850 \mathrm{~m})$. Each altitudinal site contained on average 49.5 (range 34-64) plants per region and 11 (4-19) plants per population. For the SLA measurements, five circular leaf corings were taken from newly grown, mature leaves. The diameter of the corings was either 5.5 or $9 \mathrm{~mm}$ depending on the size of the leaf. The main leaf vein was avoided during coring. Leaf corings were stored in small parchment bags and transported to the laboratory within $24 \mathrm{~h}$, dried for $48 \mathrm{~h}$ at $60^{\circ} \mathrm{C}$ and subsequently stored in a desiccator with silica gel. All leaf corings of one individual were weighed together to a precision of $0.0001 \mathrm{~g}$. The average weight of five corings 5.5 and $9 \mathrm{~mm}$ in diameter, respectively, was $0.0079 \pm 0.0022$ (standard deviation, $S D$ ) and $0.0220 \pm 0.0041 \mathrm{~g}$, respectively. The SLA was calculated as the total one-sided fresh leaf area divided by the dry weight. On 24 May 2009, rosette diameter was measured again, and the leaf thickness of one leaf per plant was measured on all transplanted plants to a precision of $0.01 \mathrm{~mm}$ using a Teclock SM-112 dial thickness gauge (Okaya, Japan).

\section{Data analysis}

To separate genetic and environmental effects on SLA, we performed a hierarchical mixed-model analysis of covariance (ANCOVA) using type-III sum of squares, employing a restricted maximum-likelihood approach, which is robust to unbalanced sampling designs. The following factors were tested: rosette diameter (fixed covariable), altitude treatment (fixed factor), region (fixed factor), population (random factor, nested in region) and the two-way interactions of altitude treatment with region and population. Rosette diameter at the time of transplantation was incorporated as a fixed covariable in order to remove a possible effect of plant age on SLA. The type-III sums of squares were calculated using JMP ver. 5.0.1.2 (SAS Institute 2003), whereas degrees of freedom, mean squares, $F$ ratios and $P$ values were calculated by hand. Tukey HSD posthoc tests $(\alpha=0.05)$ were performed in JMP to locate any significant differences for altitude treatment and region. Variance components were calculated by hand using weighted number of replicates per level.

All sampling sites in the Eastern Alps region are located at lower elevations compared to the regions to the west (Eastern Alps: 283-1,068 m a.s.l.; Western Alps, Central Swiss Alps and Central Austrian Alps: 1,340-2,266 m a.s.l.; Table 1), which probably affects climate. Climatic data for each sampled population were obtained from WorldClim (http://www.worldclim.org), which offers interpolated climate surfaces on a 2.5 -arc-min scale based on measurements from 1950 to 2000 (Hijmans et al. 2005). From the four possible WorldClim datapoints surrounding a population location, the one with the least altitudinal difference to the population location was chosen. Temperature data for any altitudinal difference was corrected for by subtracting or adding $0.0055^{\circ} \mathrm{C}$ per meter increase or decrease in altitude, respectively (Ozenda 1988). Based on yearly precipitation and yearly minimum, mean and maximum temperature (based on monthly averages), the climatic data indicates that populations in the Eastern Alps region experience a submediterranean climate that is characterized by higher temperatures and lower precipitation compared to the populations in the other three regions (Table 1). K-means clustering analysis of a dataset including climatic data and altitude of origin also showed that the Eastern Alps were clearly separated from the other three regions (data not shown). To account for these differences, we performed Pearson correlations between populationlevel SLA and altitude of origin on populations of the Eastern Alps and of the other regions separately. The coefficient of variation of population-level SLA across the three altitude sites was also correlated with altitude of origin for these two groups.

A Mantel test (Mantel 1967) was performed on pairwise population-level differences in SLA in relation with pairwise geographic population distances using 10,000 permutations to investigate isolation-by-distance. The k-means clustering analysis, the correlation analyses and the Mantel test described above were performed using the $\mathrm{R}$ statistical package ver. 2.9.2, with packages "cluster" and "ade4" (http:// www.r-project.org; R Development Core Team 2009).

To investigate the presence of natural selection on SLA, we compared quantitative trait differentiation in SLA $\left(Q_{\mathrm{ST}}\right)$ with the neutral molecular differentiation index $G^{\prime}{ }_{\mathrm{ST}}$. The latter was calculated using previously obtained microsatellite data of the populations involved (Ægisdóttir et al. 2009, Kuss et al. unpublished). As a first step, narrow-sense heritabilities $\left(h^{2}\right)$ of SLA were calculated for each population to investigate the presence of additive genetic differences among individuals (Petit et al. 2001). A reduced dataset was used containing at least two replicates per seed family per altitude and at least two seed families per altitude. Due to this restriction, six out of 18 populations had to be excluded from the dataset because of a lack of replicates (BRO, CHJ, JUA, LAH, LAL, MOI; Table 1). Narrowsense heritabilities were calculated as $h^{2}=4 V_{\mathrm{F}} /\left(4 V_{\mathrm{F}}+\mathrm{V}_{\mathrm{E}}\right)$ where $V_{\mathrm{F}}$ is the seed family variance and $V_{\mathrm{E}}$ is the residual variance. These two variance components were obtained from type-III SS random models which included rosette diameter, altitude treatment and seed family. The $Q_{\mathrm{ST}}$ of SLA was estimated among all populations based on the same dataset. Using a half-sib design, $Q_{\mathrm{ST}}$ equals $V_{\mathrm{P}} /\left(8 \times V_{\mathrm{F}}+V_{\mathrm{P}}\right)$, where $V_{\mathrm{P}}$ is the population variance. 


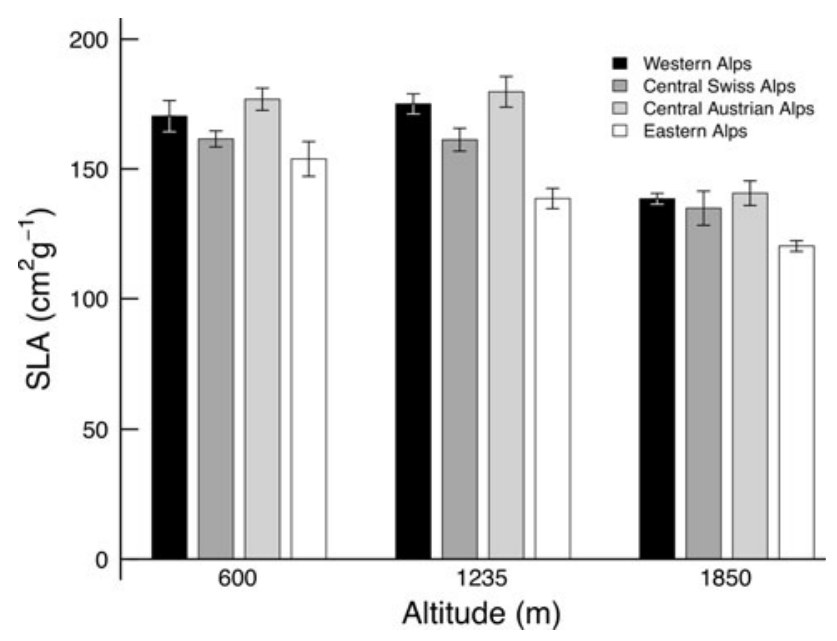

Fig. 1 Specific leaf area (SLA) of Campanula thyrsoides leaves from four biogeographic regions, measured 10 weeks after transplantation to common gardens at three different altitudes. Values are population means \pm standard error $(\mathrm{SE})$

A similar model was used to obtain the variance components $V_{\mathrm{P}}$ and $V_{\mathrm{F}}$, except that population was added as a random factor and seed family became nested in the population. In both models for $h^{2}$ and $Q_{\mathrm{ST}}$, region was left out of the analysis because this would remove genetic variability which should be attributed solely to the population and seed family levels in order to properly calculate $V_{\mathrm{P}}$ and $V_{\mathrm{F}}$. Interactions of altitude treatment with population and seed family were omitted due to insufficient replicates. Additional $Q_{\mathrm{ST}}$ values were calculated separately for the five populations from the Eastern Alps and for the seven populations from the other three regions. All models were performed using the R statistical package ver. 2.9.2, package "Ime4" (R Development Core Team 2009). Based on the same restricted set of populations, the neutral genetic differentiation index $G_{\text {ST }}^{\prime}$ (Hedrick 2005) was calculated among all populations and among the Eastern Alps and the other regions separately using SMOGD 1.2.5 (Crawford 2010). The two populations from Schynige Platte (SP18 and SP4) were not genotyped in the mentioned studies; instead, genetic data from two other populations nearby were used (SPO and SPU in Ægisdóttir et al. 2009). Variances of both indices were obtained using the Jackknife procedure over populations, and the difference between $Q_{\mathrm{ST}}$ and $G_{\mathrm{ST}}^{\prime}$ was tested by comparing their $95 \%$ confidence intervals.

\section{Results}

Phenotypic plasticity and genetic effects

Specific leaf area decreased with increasing altitude of the transplantation site (Fig. 1; $P<0.0001$; Table 2), and altitude treatment explained $22.0 \%$ of the variance in the data (Table 2). Mean SLA values of individuals from the low, intermediate and high sites were $164.9 \pm 2.2$ (mean \pm standard error, SE), $161.6 \pm 2.0$ and $132.4 \pm 1.3 \mathrm{~cm}^{2} \mathrm{~g}^{-1}$, respectively. A Tukey HSD post-hoc test on the altitude treatment revealed that the SLA at the highest site was significantly different from those at the low and intermediate sites, whereas the SLA at the two lower sites did not significantly differ from each other (Fig. 1). The difference amounts to a reduction of $18.1 \%$ in SLA across a $615-\mathrm{m}$ altitudinal difference between the intermediate and highest site. However, compared with SLA values of a set of untransplanted plants which had the remarkably higher average SLA of $268.5 \mathrm{~cm}^{2} \mathrm{~g}^{-1}$, all transplanted individuals had strongly decreased SLA values (one-way ANCOVA with rosette diameter as covariable, $F_{1,681}=950.8, P<0.0001$; data not shown).

Region was highly significant $(P<0.0001$; Table 2$)$ and accounted for $10.1 \%$ of the variation. A Tukey HSD posthoc test on region showed that the Western Alps, Central Swiss Alps and Central Austrian Alps were significantly different from the Eastern Alps. Population and the interactions of altitude treatment with region and population were not significant (Table 2) and explained only small amounts of the variance. Unexplained variance amounted to $63.8 \%$. The highly variable rosette diameter (range 3-36.5; mean \pm SE $14.16 \pm 0.26$ ) covaried significantly with SLA but
Table 2 Summary of results from the ANCOVA of environmental (three common gardens) and genetic effects (region and population) on specific leaf area

\section{ANCOVA Analysis of}

covariance

${ }^{\text {a }}$ Percentage is the proportion of the variance component

b Population is treated as a random factor and is nested in region

\begin{tabular}{|c|c|c|c|c|c|c|c|}
\hline Environmental/genetic effects & $d f$ & SS & MS & $F$ & $P$ & $V$ & Percentage \\
\hline Rosette diameter & 1 & 10,222 & 10,222 & 20.57 & $<0.0001$ & 16.37 & 2.10 \\
\hline Altitude treatment & 2 & 68,594 & 34,297 & 69.01 & $<0.0001$ & 170.96 & 21.97 \\
\hline Region & 3 & 36,545 & 12,182 & 19.29 & $<0.0001$ & 78.87 & 10.14 \\
\hline Population (region) ${ }^{\mathrm{b}}$ & 14 & 8,839 & 631 & 1.27 & 0.2214 & 4.10 & 0.53 \\
\hline Altitude treatment $\times$ region & 6 & 6,195 & 1,033 & 2.08 & 0.0542 & 10.86 & 1.40 \\
\hline $\begin{array}{l}\text { Alt treatment } \\
(\text { region })^{\mathrm{b}}\end{array}$ & 28 & 5,229 & 187 & 0.38 & 0.9986 & 0.00 & 0.00 \\
\hline Residuals & 539 & 267,879 & 497 & & & 496.99 & 63.87 \\
\hline Total & 593 & 403,504 & & & & 778.15 & 100.00 \\
\hline
\end{tabular}


explained only $2.1 \%$ of the variance (Table 2 ). Within altitudinal sites, leaf thickness decreased with increasing SLA (Pearson correlations, $600 \mathrm{~m}: r_{146}=-0.23, P=0.0046$; $1,235 \mathrm{~m}: r_{69}=-0.43, P=0.00016 ; 1,850 \mathrm{~m}: r_{101}=-0.42$, $P<0.0001)$; across altitudinal sites, leaf thickness decreased (mean $\pm \mathrm{SE}, 600 \mathrm{~m}: 0.36 \pm 0.01 \mathrm{~mm} ; 1,235 \mathrm{~m}$ : $0.31 \pm 0.01 \mathrm{~mm} ; 1,850 \mathrm{~m}: 0.30 \pm 0.00 \mathrm{~mm} ; F_{2,585}=58.9$, $P<0.0001)$ between the low and the intermediate site (Tukey HSD post-hoc test, $\alpha=0.05$ ).

\section{Adaptation versus genetic drift}

Pearson correlations of population means of SLA with altitude of origin yielded significant negative relationships only for the populations from the Eastern Alps at the low and intermediate site $(r=-0.82, P=0.046$ and $r=-0.88$, $P=0.019$, respectively; Fig. 2a, b). The coefficient of variation across altitudinal sites showed a negative relationship with altitude of origin for the Eastern Alps $(r=-0.83$, $P=0.041$ ) but not for the other three regions (Fig. 3).

The Mantel test indicated that pairwise population differences in SLA did not correlate with pairwise geographic distances $(r=-0.047, P=0.74)$. The range in narrowsense heritabilities in the 12 investigated populations was large (0.00-0.72; mean \pm SE $0.17 \pm 0.07)$, and the mean differed significantly from zero (one-sample $t$ test: $t_{11}=2.3$, $P=0.042$ ). The among-population $Q_{\mathrm{ST}}$ was 0.53 [95\% confidence interval (CI) 0.47-0.59], whereas $G_{\text {ST }}^{\prime}$ was 0.73 (95\% CI $0.70-0.77$ ), and the $95 \%$ CIs of $Q_{\mathrm{ST}}$ did not overlap with those of $G^{\prime}$ ST , indicating stabilizing selection. $Q_{\mathrm{ST}}$ was 0.22 (95\% CI -0.17 to 0.61$)$ and 0.23 (95\% CI $0.02-$ 0.44) for the Eastern Alps and the other three regions, respectively, which were both lower than their respective $G_{\text {ST }}^{\prime}$ values of 0.65 (95\% CI 0.58-0.73) and 0.55 (95\% CI 0.48-0.62), indicating comparatively strong stabilizing selection within these regions. However, the confidence

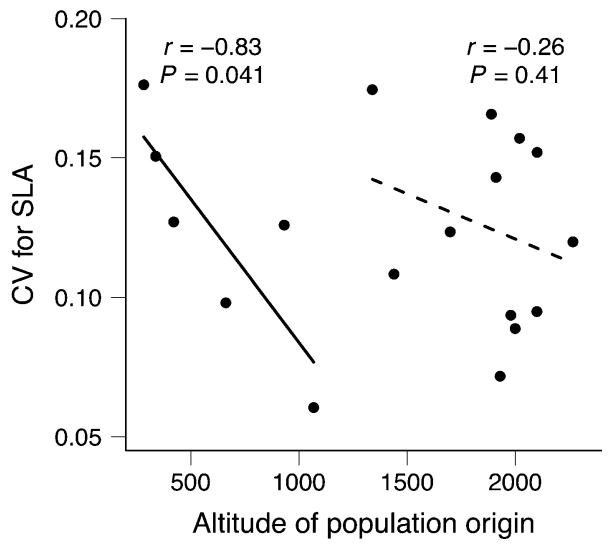

Fig. 3 Coefficient of variation $(C V)$ of population-level SLA among the altitudinal sites (i.e. the experimental sites at $600 \mathrm{~m}$ a.s.1., $1,235 \mathrm{~m}$ a.s.l. and $1,850 \mathrm{~m}$ a.s.l.) as a function of altitude of population origin ( $n=3$ for each population). Pearson's correlation coefficient $r$ and $P$ value were determined separately for Eastern Alpine populations (left) and populations from the other three regions (right)

intervals of the $Q_{\mathrm{ST}}$ and $G^{\prime}{ }_{\mathrm{ST}}$ values for the Eastern Alps overlapped, likely due to the small sample size.

\section{Discussion}

Phenotypic plasticity

Specific leaf area showed a substantial phenotypic plasticity, as indicated by the significant decrease in SLA with increasing altitude across the altitude sites 10 weeks after transplantation of the plants (Table 1; Fig. 1). The Tukey HSD post-hoc tests showed that this difference was due to lower SLA values at the highest site compared to those at the low and intermediate sites. This result indicates that the low and intermediate sites exerted equal pressure on the plants after transplantation, resulting in similar SLA values,
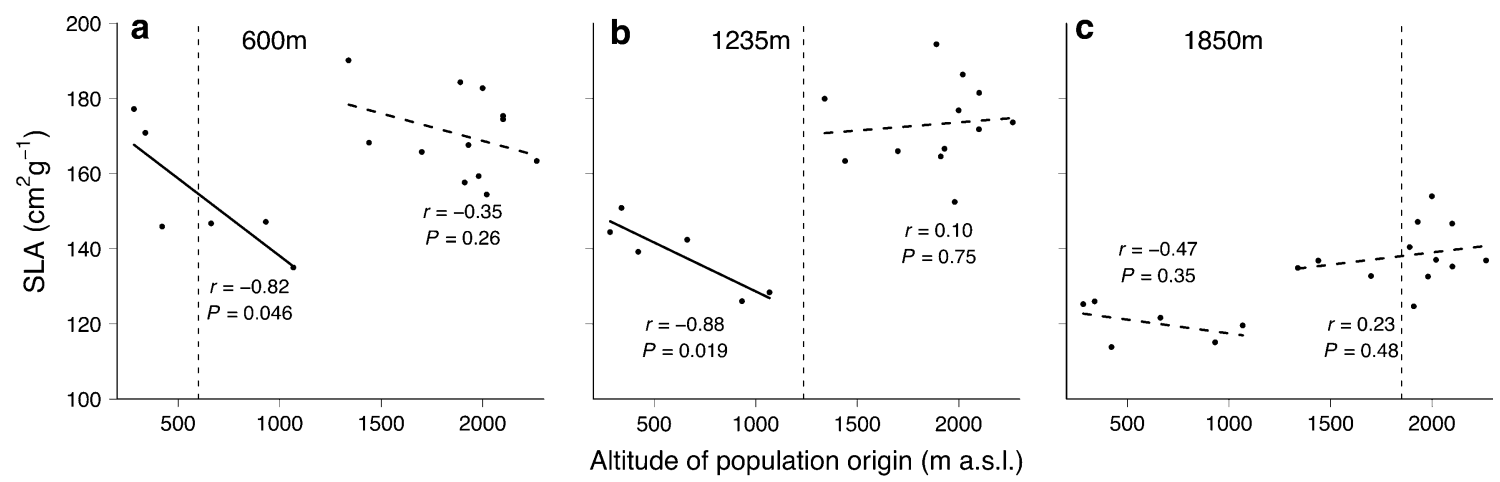

Fig. 2 Correlations between SLA and altitude of population origin at each of the three experimental altitudinal sites: a $600 \mathrm{~m}$ a.s.1., b $1,235 \mathrm{~m}$ a.s.1., c $1,850 \mathrm{~m}$ a.s.1. Data points mean population SLA for each altitudinal site. Pearson's correlation coefficient $r$ and $P$ values are given for each correlation. Separate correlations were calculated for populations from the Eastern Alps (left) and the other regions (right). Solid and dashed regression lines significant and non-significant correlations, respectively. The vertical dashed lines indicate the altitude of the experimental site 
whereas the highest site exerted stronger pressure on the plants. This effect could be caused by similar environmental conditions at the low and intermediate sites or by the exceeding of an environmental threshold value (e.g. in temperature) between the intermediate and high site to which SLA reacts sharply.

All SLA values decreased in comparison to plants which remained in the greenhouse. The higher SLA values for these control plants were likely to be due to other factors besides altitude, such as decreased light influx in the greenhouse (Poorter et al. 2009) and increased shading due to the higher density positioning of the plants. These data can therefore not be quantitatively compared to the SLA of the transplanted plants. However, it is clear that all plants showed a reaction to the transplantation, thereby allowing for the conclusion to be drawn that SLA is highly phenotypically plastic and is able to react immediately and rapidly to changing environmental conditions, such as those at contrasting altitudes.

The decrease in SLA with increasing altitude can be realized through increases in leaf density and leaf thickness (Körner 2003; Atkin et al. 2006; Poorter et al. 2009). Both increased density and increased thickness are often observed in deciduous herbs; the former through limited cell expansion leading to smaller cells and more cells per unit leaf volume, the latter through increases in the number of palisade parenchyma layers (Körner 2003; Poorter et al. 2009). These changes are explained as an investment in photosynthetically active tissue to promote efficiency in light capture (Körner 2003) and, according to Woodward (1983), this behaviour optimizes competition ability in colder climates. Leaf thickness measurements from 24 May 2009 unexpectedly showed that mean leaf thickness decreased with increasing altitude. Using the relationship $\mathrm{SLA}^{-1}=$ leaf density $\times$ leaf thickness, it can be deduced that leaf density must have increased substantially with altitude to yield the observed SLA values; this result may therefore be due to limited cell expansion.

\section{Genetic effects}

The effect of region was significant and amounted to nearly half the variance due to plasticity (Table 2), indicating that SLA is partly constrained by genetic effects. This region effect is in line with phylogeographic studies that report a genetic patterning across biogeographic regions (e.g. Schönswetter et al. 2005) which has been explained as a result of genetic drift. The present results indicate that only plants in the Eastern Alps were genetically differentiated from those of the other regions, which is in agreement with microsatellite data showing that neutral genetic differentiation was highest between plants of the Eastern Alps versus those of the other three regions (AMOVA of Eastern Alps vs. other three regions: 7.8\%; Kuss et al. unpublished). Conversely, a cluster analysis separated these two groups based on climate and altitude of origin (see Methods). Therefore, this regional differentiation is more likely to be due to local adaptation to the submediterranean climate in the Eastern Alps and to the alpine conditions in the other three regions rather than to genetic drift.

Maternal effects offer an alternative explanation to the region effect. However, maternal effects have been shown to be most prominent in the seedling phase and diminish over time (Roach and Wulff 1987). Thus, given the age of the plants (all plants were about 9 months old at the time of transplantation), it is likely that maternal effects can be rejected as explanation of the results.

Populations are expected to differ in trait values observed in common garden experiments, since natural populations occur in different environments to which they are likely to be locally adapted (Jump and Peñuelas 2005). In our study, the population factor was not significant, indicating that genetic differentiation was absent among populations within regions. This finding suggests that either environmental conditions are similar among the populations, thereby removing the need for local adaptations, or, more likely, that phenotypic plasticity is strong enough to adjust SLA to a broad range of environmental conditions. The latter can be an evolutionary answer to strong temporal variation as well as to strong spatial variation in environmental conditions (Pigliucci et al. 2003) experienced by the species through pollen and seed dispersal in the heterogeneous Alpine landscape.

Rosette diameter at the time of transplantation correlated significantly with SLA in the model, implying that age differences could have influenced SLA. The inclusion of rosette diameter in the model helped to correct for this experimental error. However, since plants from the Eastern Alps are generally larger in diameter than plants from the other regions (mean \pm SE: $19.4 \pm 0.52$ and $14.2 \pm 0.26 \mathrm{~cm}$, respectively; data not shown), rosette diameter could reduce the explanatory power from the region factor. Nevertheless, rosette diameter accounted only for a small part of the variance compared to the region effect, and region remained highly significant. The interactions of altitude treatment with region and population were not significant, which indicates that plasticity in SLA at the region and population levels were always in the same direction across the altitudinal gardens, i.e. a decrease in SLA with increasing altitude.

The variance components (Table 2) show substantial environmental as well as genotypic effects on SLA $(22.0 \%$ vs. a sum of $12.0 \%$ ). However, this result is due in part to the practicalities of the experiment; an even larger range in altitudinal sites would likely also have increased the environmental effect, given that SLA reached much higher values in the greenhouse. 
The question can be raised as to whether 10 weeks is enough time for the newly formed leaves to reach stable SLA levels. In deciduous tree species, SLA starts off low after bud burst, increases during leaf expansion and then decreases again to stable levels within 30 days (Jurik 1986). A similar pattern has been observed in wheat (Rawson et al. 1987). There was no significant difference between the average rosette diameter of the highest site at the date of sampling (2 September 2008) and that of the subsequent year (24 May 2009) (one-sided $t$ test with unequal variances, $t_{386}=1.06, P=0.15$; data not shown). This result suggests that at the time of sampling, leaves of plants at the highest site, although small in size, were fully mature and not delayed in their development relative to those at the low and intermediate sites. These observations suggest that time allotted in our study between transplantation and measurement was long enough for SLA to reach stable levels.

\section{Adaptation versus genetic drift}

Any differentiation in SLA by region and population (Table 2) could theoretically be either the result of selection leading to adaptation or the result of neutral genetic drift (Linhart and Grant 1996; Waldmann and Andersson 1998; Petit et al. 2001). The observed differentiation between the Eastern Alps and the other regions is most likely the result of adaptation to opposing climates rather than to drift. The Eastern Alpine populations are subject to a submediterranean climate, with a higher probability of summer droughts. In fact, drought (due to dry summers as well as to high mean temperatures increasing evapotranspiration) has been found to correlate with lower SLA interspecifically (Niinemets 2001) as well as intraspecifically (Fernández et al. 2002; Poorter et al. 2009). This can also be observed from Fig. 2, where the six Eastern Alpine populations to the left of each graph show decreased SLA values compared to the other populations. The heavier leaves (i.e. lower SLA) in the Eastern Alpine populations could be an adaptation to local climatic conditions, possibly through more densely cutinized epidermal walls and a thicker wax layer (Larcher 2003, p 410; Galmés et al. 2005).

To investigate the presence of genetic adaptation to altitude, we performed correlations on SLA against altitude of population origin for the two groups of populations separately (Eastern Alps and the other regions). Adaptation to altitude of origin may be expected based on the well-documented negative relationship between SLA and altitude (Cordell et al. 1998; Körner 2003). The significantly decreasing SLA with altitude of origin for the Eastern Alpine populations at the low and intermediate sites corroborate this pattern. Since the population factor was not significant in the ANCOVA, absence of any differentiation in
SLA is the best explanation for the absence of correlations in the other three regions.

The coefficient of variation of SLA (Fig. 3) showed a significant negative relationship for the Eastern Alps, indicating that the populations from lower altitudes exhibited a larger range in plasticity than those from higher altitudes within the Eastern Alps. Whether this is because the higher altitude populations were not able to respond as strongly as the lower altitude counterparts or because they did not need to adjust SLA values at the three altitudinal sites remains an open question.

The non-significant result of the Mantel test indicates that isolation-by-distance is not a good predictor of SLA. Hence, drift cannot explain the geographic distribution of the mean SLA values of the populations. The significant heritability of SLA indicated evolutionary potential, and the $Q_{\mathrm{ST}}$ vs. $G_{\mathrm{ST}}^{\prime}$ comparison showed that $Q_{\mathrm{ST}}$ was high but significantly lower than $G_{\mathrm{ST}}^{\prime}$, indicating stabilizing selection on SLA. Since the population factor was not significant in the model, the high $Q_{\mathrm{ST}}$ of 0.53 should not be taken as evidence for strong population differentiation, but rather as strong regional differentiation between the Eastern Alps and the other regions. Indeed, analysis of the populations from the Eastern Alps and the other regions separately resulted in substantially reduced $Q_{\mathrm{ST}}$ values of 0.22 and 0.23 , respectively. Since these were much lower than the respective $G_{\text {ST }}^{\prime}$ values, this is an indication for strong stabilizing selection. It can be concluded that stabilizing selection acted as a weak conservative force in the strongly divergent evolution of the Eastern Alps versus the other three regions, and as a strong conservative force within the regions.

A strong plastic response of transplanted plants to their respective altitude is well-known from the literature and has been interpreted as an adjustment to temperature (Körner 2003). The present results suggest that populations of $C$. thyrsoides would be able to survive under current climate changes by adjusting their SLA plastically. This adjustment by means of phenotypic plasticity may allow populations in the long run to adapt genetically to the environmental changes via genetic assimilation (Price et al. 2003).

\section{Conclusions}

Phenotypic plasticity in SLA is a rapid and strong process in Campanula thyrsoides, but a substantial genetic component of SLA is also present. This genetic component was shown to be due to genetic adaptation rather than to drift and appeared at two levels. First, populations in the Eastern Alps showed lower SLA values than populations from the other regions, which is likely to be an adaptation to the submediterranean climate. Second, within the Eastern Alps, 
populations showed decreasing SLA and decreasing variation in SLA with increasing altitude. Additionally, the absence of isolation-by-distance suggests that genetic drift cannot explain the geographic pattern observed for SLA. Finally, the $Q_{\mathrm{ST}}$ versus $G_{\mathrm{ST}}^{\prime}$ comparisons indicated that stabilizing selection for SLA was stronger within the regions than between them, reflecting the adaptive differentiation in SLA between the Eastern Alps and the other regions.

Acknowledgments We are grateful to Serge Aubert, director of the Station Alpine Joseph Fourier (Jardin Botanique Alpin du Lautaret), for his help in collecting plant material in the western Alps, to Guy Villaume, Olivier Bignucolo and Lucienne de Witte for help in the field, to Christine Arnold and Stephan Burkhard for weighing the leaf material, to Jens Paulsen for help with obtaining climate data and to Gemeinde Haldenstein and the CCES BioChange project of the ETH Zürich for enabling the use of field sites at Mt. Calanda. We thank Reinout Havinga, Martijn Herber, Rubén Milla and an anonymous reviewer for constructive comments on previous versions of the manuscript. This study has been supported financially by the Swiss National Science Foundation, project no. 3100AO-116785 to Jürg Stöcklin. The experiment in this study complies with the current laws of the country in which they were performed.

\section{References}

Ægisdóttir HH, Kuss P, Stöcklin J (2009) Isolated populations of a rare alpine plant show high genetic diversity and considerable population differentiation. Ann Bot 104:1313-1322

Atkin OK, Loveys BR, Atkinson LJ, Pons TL (2006) Phenotypic plasticity and growth temperature: understanding interspecific variability. J Exp Bot 57:267-281

Bradshaw AD (1965) Evolutionary significance of phenotypic plasticity in plants. Adv Genet 13:115-155

Bradshaw AD (1984) Ecological significance of genetic variation between populations. In: Dirzo R, Sarukhán J (eds) Perspectives on plant population ecology. Sinauer, Sunderland, pp 213-228

Brunies SE (1906) Die Flora des Ofengebietes. Fiebig, Chur

Clausen J, Keck D, Hiesey WM (1940) Experimental studies on the nature of plant species. I. Effect of varied environment on western North American plants. Carnegie Institution, Washington D.C.

Cordell S, Goldstein G, Mueller-Dombois D, Webb D, Vitousek PM (1998) Physiological and morphological variation in Metrosideros polymorpha, a dominant Hawaiian tree species, along an altitudinal gradient: the role of phenotypic plasticity. Oecologia 113:188-196

Crawford NG (2010) SMOGD: software for the measurement of genetic diversity. Mol Ecol Resour 10:556-557

Díaz S, Cabido M, Casanoves F (1998) Plant functional traits and environmental filters at a regional scale. J Veg Sci 9:113-122

Díaz S, Hodgson JG, Thompson K, Cabido M, Cornelissen JHC, Jalili A, Montserrat-Martí G, Grime JP, Zarrinkamar F, Asri Y, Band SR, Basconcelo S, Castro-Díez P, Funes G, Hamzehee B, Khoshnevi M, Pérez-Harguindeguy N, Pérez-Rontomé MC, Shirvany FA, Vendramini F, Yazdani S, Abbas-Azimi R, Bogaard A, Boustani S, Charles M, Dehghan M, de Torres-Espuny L, Falczuk V, Guerrero-Campo J, Hynd A, Jones G, Kowsary E, Kazemi-Saeed F, Maestro-Martínez M, Romo-Díez A, Shaw S, Siavash B, Villar-Salvador P, Zak MR (2004) The plant traits that drive ecosystems: evidence from three continents. J Veg Sci 15:295-304
Ennos RA (2001) Inferences about spatial patterns in plant populations from the analysis of molecular markers. In: Silvertown J, Antonovics $\mathbf{J}$ (eds) Integrating ecology and evolution in a spatial context. Blackwell Science, London, pp 45-71

Fernández RJ, Wang M, Reynolds JF (2002) Do morphological changes mediate plant responses to water stress? A steady-state experiment with two $\mathrm{C}_{4}$ grasses. New Phytol 155:79-88

Galen C, Shore JS, Deyoe H (1991) Ecotypic divergence in alpine Polemonium viscosum: genetic structure, quantitative variation, and local adaptation. Evolution 45:1218-1228

Galmés J, Cifre J, Medrano H, Flexas J (2005) Modulation of relative growth rate and its conmponents by water stress in Mediterranean species with different growth forms. Oecologia 145:21-31

Grime JP (1977) Evidence for the existence of three primary strategies in plants and its relevance to ecological and evolutionary theory. Am Nat 111:1169-1195

Hedrick PW (2005) A standardized genetic differentiation measure. Evolution 59:1633-1638

Hijmans RJ, Cameron SE, Parra JL, Jones PG, Jarvis A (2005) Very high resolution interpolated climate surfaces for global land areas. Int J Climatol 25:1965-1978

Jump AS, Peñuelas J (2005) Running to stand still: adaptation and the response of plants to rapid climate change. Ecol Lett 8:1010-1020

Jurik TW (1986) Temporal and spatial patterns of specific leaf weight in successional northern hardwood tree species. Am $\mathrm{J}$ Bot 73:1083-1092

Kawecki TJ, Ebert D (2004) Conceptual issues in local adaptation. Ecol Lett 7:1225-1241

Körner C (2003) Alpine plant life, 2nd edn. Springer, Heidelberg

Kuss P, Ægisdóttir HH, Stöcklin J (2007) The biological flora of Central Europe: Campanula thyrsoides L. Perspect Plant Ecol 9:37-51

Kuss P, Rees M, Ægisdóttir HH, Ellner SP, Stöcklin J (2008) Evolutionary demography of long-lived monocarpic perennials: a time-lagged integral projection model. J Ecol 96:821-832

Larcher W (2003) Physiological plant ecology, 4th edn. Springer, Heidelberg

Lavorel S, Garnier E (2002) Predicting changes in community composition and ecosystem functioning from plant traits: revisiting the Holy Grail. Funct Ecol 16:545-556

Linhart YB, Grant MC (1996) Evolutionary significance of local genetic differentiation in plants. Annu Rev Ecol Syst 27:237-277

Mantel N (1967) The detection of disease clustering and a generalized regression approach. Cancer Res 27:209-220

McKay JK, Latta RG (2002) Adaptive population divergence: markers, QTL and traits. Trends Ecol Evol 17:285-291

Merxmüller H (1952) Untersuchungen zur Sippengliederung and Arealbildung in den Alpen. I. Jahrb Vereins Schutze Alpenpflanz Tiere 17:96-133

Merxmüller H (1953) Untersuchungen zur Sippengliederung and Arealbildung in den Alpen. II. Jahrb Vereins Schutze Alpenpflanz Tiere 18:138-158

Merxmüller H (1954) Untersuchungen zur Sippengliederung and Arealbildung in den Alpen. III. Jahrb Vereins Schutze Alpenpflanz Tiere 19:97-139

Milla R, Giménez-Benavides L, Escudero A, Reich PB (2009) Intraand interspecific performance in growth and reproduction increase with altitude: a case study with two Saxifraga species from northern Spain. Funct Ecol 23:111-118

Monty A, Mahy G (2009) Clinal differentiation during invasion: Senecio inaequidens (Asteraceae) along altitudinal gradients in Europe. Oecologia 159:305-315

Morecroft MD, Woodward FI (1996) Experiments on the causes of altitudinal differences in the leaf nutrient contents, size and $\delta^{13} \mathrm{C}$ of Alchemilla alpina. New Phytol 134:471-479 
Niinemets Ü (2001) Global-scale climatic controls of leaf dry mass per area, density, and thickness in trees and shrubs. Ecology 82:453-469

Ozenda P (1988) Die Vegetation der Alpen im Europäischen Gebirgsraum. Fischer, Stuttgart

Petit C, Fréville H, Mignot A, Colas B, Riba M, Imbert E, HurtrezBoussés S, Virevaire M, Olivieri I (2001) Gene flow and local adaptation in two endemic plant species. Biol Conserv 100:21-34

Pigliucci M, Pollard H, Cruzan MB (2003) Comparative studies of evolutionary responses to light environments in Arabidopsis. Am Nat 161:68-82

Poorter H, Niinemets Ü, Poorter L, Wright IJ, Villar R (2009) Causes and consequences of variation in leaf mass per area (LMA): a meta-analysis. New Phytol 182:565-588

Price TD, Qvarnström A, Irwin DE (2003) The role of phenotypic plasticity in driving genetic evolution. Proc Royal Soc Lond Ser B 270:1433-1440

R Development Core Team (2009) R: a language and environment for statistical computing. R Foundation for Statistical Computing, Vienna

Rawson HM, Gardner PA, Long MJ (1987) Sources of variation in specific leaf area in wheat grown at high temperature. Aust J Plant Physiol 14:287-298

Roach DA, Wulff RD (1987) Maternal effects in plants. Annu Rev Ecol Syst 18:209-235

Rogers AR (1986) Population differences in quantitative characters as opposed to gene frequencies. Am Nat 127:729-730

SAS Institute (2003) JMP version 5.0.1.2. SAS, Cary

Schlichting CD (1986) The evolution of phenotypic plasticity in plants. Annu Rev Ecol Syst 17:667-694

Schönswetter P, Stehlik I, Holderegger R, Tribsch A (2005) Molecular evidence for glacial refugia of mountain plants in the European Alps. Mol Ecol 14:3547-3555
Sims DA, Pearcy RW (1992) Response of leaf anatomy and photosynthetic capacity in Alocasia macrorrhiza (Araceae) to a transfer from low to high light. Am J Bot 79:449-455

Spitze K (1993) Population structure in Daphnia obtusa: quantitative genetic and allozyme variation. Genetics 135:367-374

Sultan S (2000) Phenotypic plasticity for plant development, function and life history. Trends Plant Sci 5:537-542

Turesson G (1922) The genotypical response of the plant species to habitat. Hereditas 3:211-350

Waldmann P, Andersson S (1998) Comparison of quantitative genetic variation and allozyme diversity within and between populations of Scabiosa canescens and S. columbaria. Heredity 81:79-86

Weiher E, Keddy PA (1999) Assembly rules as general constraints on community composition. In: Weiher E, Keddy PA (eds) Ecological assembly rules: perspectives, advances, retreats. Cambridge University Press, Cambridge, pp 251-271

Weiher E, Van der Werf A, Thompson K, Roderick M, Garnier E, Eriksson O (1999) Challenging Theophrastus: a common core list of plant traits for functional ecology. J Veg Sci 10:609-620

Westoby M, Wright IJ (2006) Land plant ecology on the basis of functional traits. Trends Ecol Evol 21:261-268

Woodward FI (1983) The significance of interspecific differences in specific leaf area to the growth of selected herbaceous species from different altitudes. New Phytol 95:313-323

Wright IJ, Westoby M (2002) Leaves at low versus high rainfall: coordination of structure, lifespan and physiology. New Phytol 155:403-416

Wright IJ, Reich PB, Westoby M, Ackerly DD, Baruch Z, Bongers F, Cavender-Bares J, Chapin T, Cornelissen JHC, Diemer M, Flexas J, Garnier E, Groom PK, Gulias J, Hikosaka K, Lamont BB, Lee T, Lee W, Lusk C, Midgley JJ, Navas ML, Niinemets Ü, Oleksyn J, Osada N, Poorter H, Poot P, Prior L, Pyankov VI, Roumet C, Thomas SC, Tjoelker MG, Veneklaas EJ, Villar R (2004) The worldwide leaf economics spectrum. Nature 428:821-827 